\title{
Determining the susceptibility of carbapenem resistant Klebsiella pneumoniae and Escherichia coli strains against common disinfectants at a tertiary hospital in China
}

\author{
Yili Chen ${ }^{1}$, Kang Liao ${ }^{1}$, Yongxin Huang ${ }^{2}$, Penghao Guo ${ }^{1}$, Han Huang ${ }^{1}$, Zhongwen Wu ${ }^{1}$ and Min Liu ${ }^{1 *}$
}

\begin{abstract}
Background: Carbapenem-resistant Enterobacteriaceae (CRE) infections have become a global health threat. Controlling CRE transmission in hospitals is increasingly dependent on the use of disinfectants to restrict the risk of infection. Here, the susceptibility of patient-derived carbapenem resistant Klebsiella pneumoniae (CRKP) and Escherichia coli (CREC) strains against three common disinfectants and the determinants of resistance to disinfectants were investigated.

Methods: The minimum inhibitory concentrations (MICs) and the minimum bactericidal concentrations (MBCs) of three common chemical disinfectants: chlorhexidine, trichloroisocyanuric (TCCA) acid and Povidone iodine (PVP-I) against 50 CRE strains were measured. The drug-resistance genes -qacE $\Delta$ 1, qacA/B and cepA-were determined using polymerase chain reaction.

Results: A total of 36 CRKP and 14 CREC strains were collected in our hospital from 2016 to 2018. The MIC ranges of 36 CRKP strains against chlorhexidine, TCCA and PVP-I were $8 \sim 512 \mathrm{mg} / \mathrm{L}, 64 \sim 128 \mathrm{mg} / \mathrm{L}$ and $8 \sim 128 \mathrm{mg} / \mathrm{L}$, respectively. For 14 CREC strains, the MIC ranges against chlorhexidine, TCCA and PVP-I were 4 128 mg/L, 64 128 $\mathrm{mg} / \mathrm{L}$ and $4 \sim 128 \mathrm{mg} / \mathrm{L}$, respectively. Moreover, against chlorhexidine and PVP-I, the MIC 90 of 36 CRKP strains was higher than that of 50 CSKP strains. The gacE 1 gene was detected in 15 isolates among 36 CRKP strains (41.7\%), and 8 isolates among 14 CREC strains (57.1\%); while the gacA/B gene was not detected. Specifically, the cepA gene was much more prevalent than the gacE $\Delta 1$; it reached over $80 \%$ among CRKP strains. Compared to the CSKP strains, the presence of the qacE $\Delta 1$ and cepA genes was significantly higher among the CRKP strains $(p<0.05)$.

Conclusion: CRE strains collected from patients in our hospital exhibit various degree of resistance to the commonly used chemical disinfectants. It is of great help to keep monitoring the tendency of the reduced susceptibility of the pan-resistant strains against disinfectants, in order to effectively control and prevent the spread of the super resistant bacteria.
\end{abstract}

Keywords: Carbapenem resistant, Klebsiella pneumonia, Escherichia coli, Disinfectant, susceptibility

\footnotetext{
* Correspondence: nancy20151031@163.com

${ }^{1}$ Department of Laboratory Medicine, The First Affiliated Hospital of Sun

Yat-sen University, Guangzhou 510080, Guangdong, China

Full list of author information is available at the end of the article
}

(c) The Author(s). 2020 Open Access This article is distributed under the terms of the Creative Commons Attribution 4.0 International License (http://creativecommons.org/licenses/by/4.0/), which permits unrestricted use, distribution, and reproduction in any medium, provided you give appropriate credit to the original author(s) and the source, provide a link to the Creative Commons license, and indicate if changes were made. The Creative Commons Public Domain Dedication waiver (http://creativecommons.org/publicdomain/zero/1.0/) applies to the data made available in this article, unless otherwise stated. 


\section{Background}

Carbapenem-resistant Enterobacteriaceae (CRE) is a globally important nosocomial pathogen. Infections caused by CRE are associated with increased morbidity and mortality rates and greater hospital costs [1, 2]. CREinfected patients often suffer multiple underlying diseases and are in immunosuppression. Effective drugs to eliminate this infection from the patients are limited currently. Therefore, strategies to prevent initial infection by eliminating or at least reducing the presence of this bacteria in the clinical environment is of significant importance, and should be given a high priority by clinicians [3].

Disinfectants are extensively applied to control infectious organisms from potentially contaminated equipment and specimens. However, like the emergence of antibiotic resistance, drug-resistant bacteria may gradually become resistant to the commonly used clinical chemical disinfectants, especially because of the possible similar mechanisms between antibiotic resistance and disinfectant resistance [4]. The excessive use of disinfectants imposed selective pressure on strains, causing a wide distribution of disinfectant resistance genes. Many disinfectant resistance genes have been confirmed in multidrug-resistant bacteria, such as qacA/B, qacE, qacE $\Delta 1$, qacG, qac), серA, $\operatorname{arc} A$ and $k d e A$ [5-7].

Effectiveness of disinfectants against Enterobacteriaceae was reported previously [8-10]. However, less information about disinfectant effectiveness against carbapenem-resistant Enterobacteriaceae (CRE) is available. In this study, carbapenem resistant Klebsiella pneumoniae (CRKP) and Escherichia coli (CREC) strains were isolated from patients at the First Affiliated Hospital of Sun Yat-sen University. The minimum inhibitory concentration (MIC) and minimum bactericidal concentration (MBC) of the commonly used disinfectants against each CRE strain were determined. Moreover, the presence of relevant resistance genes was determined.

\section{Methods}

\section{Isolation and identification of bacterial strains}

A total of 36 CRKP and 14 CREC strains with ertapenem MICs $\geq 2 \mu \mathrm{g} / \mathrm{ml}$ were collected in the First Affiliated Hospital of Sun Yat-sen University from 2016 to 2018. Meanwhile, 50 strains of carbapenem susceptible Klebsiella pneumoniae (CSKP) and 30 strains of carbapenem susceptible Escherichia coli (CSEC) were collected as control group strains (ertapenem $\mathrm{MICs} \leq 0.5 \mu \mathrm{g} / \mathrm{ml}$ ). Clinical specimens were collected from urine, blood, sputum, sterile body fluid and wound secretion. Identification of isolates was performed using an automated microbiology analyzer (bioMérieux, Marcy l'Etoile, France) according to the manufacturer's instructions. The standard strains included Klebsiella pneumoniae ATCC 700603 and Escherichia coli ATCC 25922.

\section{Antimicrobial susceptibility testing}

Antimicrobial susceptibilities for isolates were detected initially by Gram-negative susceptibility (GNS) cards on the Vitek system (bioMérieux, Marcy l'Etoile, France). Antimicrobials evaluated included piperacillintazobactam, ampicillin-sulbactam, levofloxacin, ceftriaxone, ceftazidime, cefotaxime, imipenem, cefepime, ampicillin /clavulanic acid cefoxitin, ciprofloxacin, and amikacin. Susceptibility testing results were interpreted under the criteria recommended by the Clinical and Laboratory Standards Institute (CLSI, 2018). The quality control strain for susceptibility testing was E. coli ATCC 25922.

\section{PFGE}

Pulsed-field gel electrophoresis (PFGE) analysis was performed as described previously with the $\mathrm{XbaI}$ restriction endonuclease (TAKARA, Shiga, Japan) [11] and the Fingerprinting II Informatix software package system (BioRad Laboratories, Hercules, CA). The similarity of the PFGE banding patterns was calculated by the Dice coefficient, and the data acquired were carried out by the unweighted pair group method with arithmetic average (UPGMA) clustering by the Pearson correlation coefficient.

\section{Disinfectants and neutralizers}

In the study, three disinfectants were used, and they were $0.1 \%$ chlorhexidine (Chinese Co., Ltd., Jinzhou, China), trichloroisocyanuric acid (TCCA) (Changjiang Mai Medicine Technology Co., Ltd., Beijing, China) and 0.1\% Povidone iodine (PVP-I) (An Duo Fu, Shenzhen, China). Table 1 shows the neutralizing agents used to inhibit each of the disinfectants.

\section{Testing the MICs and MBCs for the effectiveness of each disinfectant}

$\mathrm{MIC}_{\mathrm{S}}$ (minimum inhibitory concentrations) of the three disinfectants against CRKP and CREC clinical isolates were determined by micro-broth dilution method according to the guidelines of the CLSI (CLSI, 2018), in concentrations that ranged from $1 \sim 512 \mathrm{mg} / \mathrm{L}$ for

Table 1 Neutralizers used to neutralize the three chemical disinfectants respectively

\begin{tabular}{ll}
\hline Disinfectants & Neutralizers \\
\hline $0.1 \%$ chlorhexidine & $5.0 \%$ Tween 80 \\
TCCA & $1000 \mathrm{ml}$ PBS $+5 \mathrm{~g}$ sodium thiosulfate + \\
& $0.5 \%$ Tween 80 \\
$0.1 \%$ PVP-I & $1000 \mathrm{ml} \mathrm{PBS}+10 \mathrm{~g}$ sodium thiosulfate + \\
& $1.0 \%$ Tween 80 \\
\hline
\end{tabular}


chlorhexidine, 2 1024 mg/L for TCCA, and 1 512 mg/L for $0.1 \%$ PVP-I. Firstly, the standard bacterial concentration of McFarland standard 0.5 was applied $\left(1.5 \times 10^{8} \mathrm{cfu} /\right.$ $\mathrm{mL}$ ). The $0.5 \mathrm{McF}$ arland inoculum suspensions were further diluted at 1: 100 in Luria Broth (LB) before inoculation. $50 \mu \mathrm{L}$ of bacterial suspension was added from wells 1 to 12 in a 96-well plate, followed with $50 \mu \mathrm{lL}$ chlorhexidine, TCCA or $0.1 \%$ PVP-I. LB without disinfectant was inoculated with the bacteria and used as the positive control, while LB alone was used as the negative control. The plates were incubated at $37^{\circ} \mathrm{C}$ overnight. After the $24 \mathrm{~h}$ incubation for MIC determination, the reactions from the above MIC tests that did not exhibit bacterial growth were selected, and $0.05 \mathrm{~mL}$ of the sterile reaction was transferred into $0.45 \mathrm{~mL}$ neutralizer specific for the particular disinfectant used in each test. The solution was mixed thoroughly and incubated at room temperature for $10 \mathrm{~min}$ as the final reaction solution. $0.5 \mathrm{~mL}$ of the each mixed solution was used to coat in a $\mathrm{MH}$ agar plate. Samples were incubated at $37^{\circ} \mathrm{C}$ for $24 \mathrm{~h}$. The minimum concentration of the disinfectant corresponding to the sterile plate was determined to be the MBCs (minimum bactericidal concentrations) of the disinfectant against the tested bacterial strain. The positive and negative control groups were prepared as described above in the MIC experiment, and solutions containing $0.45 \mathrm{~mL}$ of a neutralizer plus $0.05 \mathrm{~mL}$ of the LB were used as the controls for the neutralizers. Experiments were performed in triplicate, with consistent results.

PCR detection and sequence analysis of resistance genes Bacterial DNA was extracted from CRKP and CREC isolates by boiling. PCR of resistance genes qacE $\Delta 1$, qacA/B and cep $A$ was performed using TaKaRa Ex Taq (Takara Bio Inc., Otsu, Japan) on the Applied Biosystems ${ }^{\circ} 7500$ Fast Dx Real-Time PCR Instrument (Life Technologies Corporation, Foster City, CA). All PCR primers targeting resistance genes used in this study are listed in Table 2. Appropriate positive and negative controls for amplification were selected from clinical Klebsiella pneumoniae isolates. The positive controls that carried the resistance genes were confirmed using PCR followed by sequence analysis. Each $20 \mu \mathrm{L}$ PCR tube included $2 \mu \mathrm{L}$ DNA template, $6 \mu \mathrm{L}$ sterile water, $1 \mu \mathrm{L}$ forward primer (Sangon

Table 2 Primer sequences of the target genes

\begin{tabular}{llcc}
\hline Gene & Primer Sequence $\left(5^{\prime} \rightarrow 3^{\prime}\right)$ & Size $(\mathrm{bp})$ & Reference \\
\hline qacE $\Delta 1$ & F: TAGCGAGGGCTTACTAAGC & 300 & {$[12]$} \\
& R: ATTCAGAATGCCGAACACCG & & \\
qacA/B & F: CTATGGCAATAGGAGATATGGTGT & 416 & {$[3]$} \\
& R: CCACTACAGATTCTTCAGCTACATG & & \\
cepA & F: CAACTCCTTCGCCTATCCCG & 1051 & {$[12]$} \\
& R: TCAGGTCAGACCAAACGGCG & & \\
\hline
\end{tabular}

Biotech), $1 \mu \mathrm{L}$ reverse primer and $10 \mu \mathrm{L} 2 \mathbf{X}$ Taq Master Mix (Takara Bio Inc., Otsu, Japan). The PCR conditions was set as follows: $94{ }^{\circ} \mathrm{C}$ for $5 \mathrm{~min}$, followed by 30 cycles of $94{ }^{\circ} \mathrm{C}$ for $30 \mathrm{~s}$ for denaturation, $53^{\circ} \mathrm{C}$ for $30 \mathrm{~s}$ for annealing and $72^{\circ} \mathrm{C}$ for $1 \mathrm{~min}$ for extension. Finally, the PCR products were incubated at $72{ }^{\circ} \mathrm{C}$ for $10 \mathrm{~min}$. Amplified PCR products were analyzed on $1 \%$ agarose gel (Fisher Scientifific, Loughborough, UK). Amplicons were sequenced by Shanghai Sangon Bioengineering using an ABI 3730 sequencer (Applied Biosystems ${ }^{\circ}$ ) with the same primers as used for PCR amplification.

\section{Statistical analysis}

The MICs and MBCs were analysed by Manne-Whitney test. Differences in MIC and MBC distribution were compared by testing for equality of populations using the Kruskal-Wallis test. Presentation of resistance genes results was analysed by the unpaired $t$-test. Differences with a $P$-value of $<0.05$ were considered to be statistically significant.

\section{Results \\ Antimicrobial susceptibility profile}

Among the 50 strains of carbapenem-resistant Enterobacteriaceae (CRE) with ertapenem $\mathrm{MICs} \geq 2 \mu \mathrm{g} / \mathrm{ml}$, one strain of $K$. pneumoniae showed susceptible to imipenem with $\mathrm{MIC}=1 \mu \mathrm{g} / \mathrm{ml}$. Most of the agents exhibited very high resistance rates (Table 3 ).

\section{Genetic diversity}

In Fig. 1, it showed the PFGE typing from 50 CRE strains. The 36 CRKP were divided into 16 unique PFGE types, which suggests that the majority $(16 / 36)$ of the isolates were considered distinct as they demonstrated < $85 \%$ similarity with any other isolate. The 14 CREC strains belonged to 5 different PFGE clusters, indicating that they were disseminated horizontally through the population and not just by the spread of a single strain.

\section{Sensitivity of the clinically isolated strains to each disinfectant}

In general, compared with the reference strains, we observed higher MICs and MBCs of chlorhexidine and PVP-I (Table 4). Specially, the MICs of chlorhexidine against CRKP and CREC ranged from 8 to $512 \mathrm{mg} / \mathrm{L}\left(\mathrm{MIC}_{90}=32 \mathrm{mg} / \mathrm{L}\right)$, and 4 to $128 \mathrm{mg} / \mathrm{L}\left(\mathrm{MIC}_{90}=16 \mathrm{mg} / \mathrm{L}\right)$, respectively, which were generally higher than those observed for $K$. pneumoniae ATCC 700603 and $E$. coli ATCC 25922 reference strains (16 $\mathrm{mg} / \mathrm{L}$ and $2 \mathrm{mg} / \mathrm{L}$, respectively). There were significant differences in MIC and MBC distribution between the CRKP(CREC) strains and CSKP(CSEC) strains against chlorhexinine and PVP-I $(p<0.05)$. Moreover, against chlorhexidine or PVP-I, the $\mathrm{MIC}_{90}$ of 36 CRKP strains was higher than that of 50 CSKP strains $(p<0.05)$, suggesting a 
Table 3 Antimicrobial susceptibility test results of the 50 strains of carbapenem-resistant Enterobacteriaceae (CRE)

\begin{tabular}{|c|c|c|c|c|c|c|}
\hline \multirow[t]{2}{*}{ Antibiotics } & \multicolumn{3}{|c|}{$\operatorname{CRKP}(n=36)$} & \multicolumn{3}{|c|}{$\operatorname{CREC}(n=14)$} \\
\hline & Resistant & Intermediate & Susceptible & Resistant & Intermediate & Susceptible \\
\hline ETP & $100 \%$ & 0 & 0 & $100 \%$ & 0 & 0 \\
\hline IMP & $94.4 \%$ & $2.78 \%$ & $2.78 \%$ & $100 \%$ & 0 & 0 \\
\hline FEP & $100 \%$ & 0 & 0 & $100 \%$ & 0 & 0 \\
\hline CAZ & $100 \%$ & 0 & 0 & $100 \%$ & 0 & 0 \\
\hline TZP & $100 \%$ & 0 & 0 & $100 \%$ & 0 & 0 \\
\hline AMK & $86.1 \%$ & 0 & $13.9 \%$ & $92.9 \%$ & 0 & $7.14 \%$ \\
\hline FOX & $100 \%$ & 0 & 0 & $100 \%$ & 0 & 0 \\
\hline SAM & $100 \%$ & 0 & 0 & $100 \%$ & 0 & 0 \\
\hline LEV & $94.5 \%$ & 0 & $5.55 \%$ & $85.7 \%$ & 0 & $14.3 \%$ \\
\hline $\mathrm{CIP}$ & $97.2 \%$ & 0 & $2.78 \%$ & $85.7 \%$ & 0 & $14.3 \%$ \\
\hline CTX & $100 \%$ & 0 & 0 & $100 \%$ & 0 & 0 \\
\hline $\mathrm{CRO}$ & $100 \%$ & 0 & 0 & $100 \%$ & 0 & 0 \\
\hline
\end{tabular}

ETP ertapenem, IMP imipenem, FEP cefepime, CAZ ceftazidime, TZP piperacillin-tazobactam, AMK amikacin, FOX cefoxitin, SAM ampicillin-sulbactam, LEV levofloxacin, CIP ciprofloxacin, CTX cefotaxime, CRO ceftriaxone

decreased sensitivity of carbapenem-resistant strains against the common used disinfectants.

PCR detection of relevant drug-resistance genes qacE $\triangle 1$, qacA/B and cepA

Among 36 CRKP strains, 41.7\% (15/36) of them were positive for $q a c E \Delta 1$, and $80.6 \%$ (29/36) for $\operatorname{cepA}$, which was much higher than that in CSKP group $(p<0.05)$ (Table 5). Among 14 CREC strains, the qacE 1 and cepA genes were more frequently amplified in 8 (57.1\%) and $7(50.0 \%)$ than CSEC group $(p<0.05)$, respectively. None of the tested CRE strains were positive for $q a c A / B$. Specially, isolates carrying the qacE $\Delta 1$ gene were significantly less susceptible to chlorhexidine and PVP-I than


(B)

(A)

Fig. 1 PFGE typing of 50 CRE strains. a Cluster analysis of 36 carbapenem-resistant K. pneumoniae (CRKP) strains; b Cluster analysis of 14 carbapenem-resistant E. coli (CREC) strains 
Table 4 Sensitivity of the clinically isolated strains to each of the disinfectants

\begin{tabular}{|c|c|c|c|c|c|c|c|c|c|}
\hline \multirow{2}{*}{$\begin{array}{l}\text { Disinfectants } \\
\text { Isolates }\end{array}$} & \multicolumn{3}{|l|}{ Chlorhexidine } & \multicolumn{3}{|l|}{ TCCA } & \multicolumn{3}{|l|}{ PVP-I } \\
\hline & $\begin{array}{l}\text { MIC } \\
\text { (mg/L) range }\end{array}$ & $\begin{array}{l}\mathrm{MIC}_{90} \\
(\mathrm{mg} / \\
\mathrm{L})\end{array}$ & $\begin{array}{l}\mathrm{MBC} \\
\text { (mg/L) range }\end{array}$ & $\begin{array}{l}\text { MIC } \\
(\mathrm{mg} / \mathrm{L}) \text { range }\end{array}$ & $\begin{array}{l}\mathrm{MIC}_{90} \\
(\mathrm{mg} / \\
\mathrm{L})\end{array}$ & $\begin{array}{l}\mathrm{MBC} \\
(\mathrm{mg} / \mathrm{L}) \text { range }\end{array}$ & $\begin{array}{l}\text { MIC } \\
\text { (mg/L) range }\end{array}$ & $\begin{array}{l}\mathrm{MIC}_{90} \\
(\mathrm{mg} / \\
\mathrm{L})\end{array}$ & $\begin{array}{l}\mathrm{MBC} \\
(\mathrm{mg} / \mathrm{L}) \text { range }\end{array}$ \\
\hline CRKP $(n=36)$ & $8 \sim 512$ & 32 & $8 \sim 512$ & $64 \sim 128$ & 128 & $64 \sim 256$ & $8 \sim 128$ & 32 & $8 \sim 128$ \\
\hline $\operatorname{CSKP}(n=50)$ & $8 \sim 256$ & 16 & $8 \sim 256$ & $64 \sim 128$ & 128 & $64 \sim 128$ & $4 \sim 64$ & 16 & $4 \sim 64$ \\
\hline $\begin{array}{l}\text { ATCC } \\
700,603\end{array}$ & 16 & & 16 & 128 & & 128 & 16 & & 16 \\
\hline $\operatorname{CREC}(n=14)$ & $4 \sim 128$ & 16 & $4 \sim 128$ & $64 \sim 128$ & 128 & $64 \sim 128$ & $4 \sim 128$ & 32 & $4 \sim 128$ \\
\hline $\operatorname{CSEC}(n=30)$ & $2 \sim 128$ & 8 & $2 \sim 128$ & $64 \sim 128$ & 128 & $64 \sim 128$ & $4 \sim 64$ & 32 & $4 \sim 64$ \\
\hline $\begin{array}{l}\text { ATCC } \\
25,922\end{array}$ & 2 & & 2 & 128 & & 128 & 32 & & 32 \\
\hline
\end{tabular}

those without carrying $q a c E \Delta 1$ gene $(p<0.05)$ (Figs. 2 and 3).

\section{Discussion}

In this study, 50 CRE strains all exhibited resistance to ertapenem as well as the third and fourth generation of cephalosporins. In the clinic, there are limited options of antibiotic drugs available for treating CRE infections currently. Thus, the consequences of an outbreak may be serious, and effective strategies to fight against the presence of CRE in the hospital environment are essential to control the spread of this infection.

In the present study, we chose three clinically common used disinfectants, chlorhexidine acetate, trichloroisocyanuric acid and PVP-I, which are topical disinfectants with a broad spectrum of activity. They are widely used in hospitals in different applications such as hand hygiene, skin preparation before invasive operation and surface cleaning [13-15]. Significantly, it is very likely that, the same as the emergence antibiotic resistance, the drug resistant strains will also gradually grow resistant to the clinically common used disinfectants [3]. Indeed, there were significant differences in MIC and $\mathrm{MBC}$ distribution between the CRKP(CREC)strains and CSKP(CSEC)strains against chlorhexinine and PVP-I in this study, suggesting a decreased sensitivity of carbapenemresistant strains against the common used disinfectants.

The presence of the qacE $\Delta$ land cepA genes plays a potential role on increasing the level MICs against disinfectants [6]. It is reported that the genes, qacE $\Delta 1$ and cepA, have a close relationship with decreasing antiseptic susceptibility in Enterobacteriaceae strains [12]. Usually, the qacEA1 gene was located upstream of the sul1 sulfonamide resistance gene and downstream of the aminoglycoside adenyltransferase gene (aadA1) directly, which was flanked by the dihydrofolate reductase gene dhfrAl. The qacE $\Delta 1$ gene seems to be part of a small resistance island indicating that this gene is related and migrates with antibiotic resistance genes. The close relationship of qac genes to antibiotic resistance genes has been proved previously in resistance islands. The widespread carriage of qac genes in $K$. pneumoniae [6] and their linkage to antibiotic resistance genes suggests that excessively use of antiseptics could select antibiotic-resistant strains.

Our study demonstrated that over $40 \%$ of the CRE strains carried the two genes qacE $\Delta 1$ and cepA. Specifically, the cepA gene was much more prevalent than the qacE $\triangle 1$; it reached over $80 \%$ among CRKP strains. Compared to the CSKP strains, the presence of the qacEA1 and серA genes was significantly higher among the CRKP strains, suggesting that CRKP strains harbouring drug-resistance genes might have potentially higher tolerance to growth inhibition or killing by disinfectants than those susceptible strains.

Chlorhexidine is a cationic biguanide antiseptic. In present study, the MIC values of CRKP and CREC against chlorhexidine were found to be 8 to $512 \mathrm{mg} / \mathrm{L}$, and 4 to $128 \mathrm{mg} / \mathrm{L}$, respectively. Previous reports have described reduced susceptibility to chlorhexidine among $K$. pneumoniae strains; but the most frequently reported MIC, using the agar dilution method, was $32 \mu \mathrm{g} / \mathrm{mL}[7,13]$, which was consistent with our result. In the study of

Table 5 Detection of the disinfectant-resistance genes among CRE strains and non-CRE strains

\begin{tabular}{llllll}
\hline & qacE $\Delta 1$ & qacA/B & cepA \\
\hline CRKP & $41.7 \%(15 / 36)$ & $p>0.05$ & 0 & - & $80.6 \%(29 / 36)$ \\
CSKP & $36.0 \%(18 / 50)$ & & 0 & $58.0 \%(29 / 50)$ & $p<0.05$ \\
CREC & $57.1 \%(8 / 14)$ & $p<0.05$ & 0 & $p>0.05$ & $50.0 \%(7 / 14)$ \\
CSEC & $33.3 \%(10 / 30)$ & & $3.33 \%(1 / 30)$ & & $33.3 \%(10 / 30)$ \\
\hline
\end{tabular}




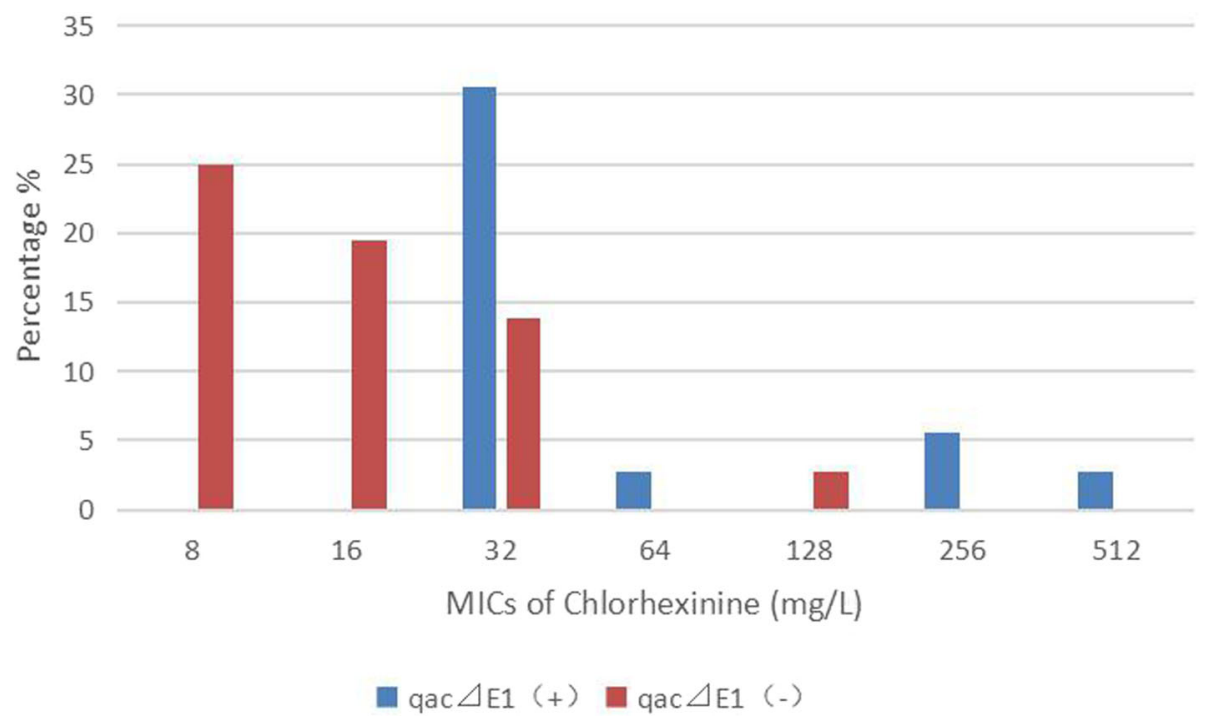

Fig. 2 Distribution of the minimum inhibitory concentrations of chlorhexidine among 36 CRKP strains. Isolates carrying the qacE $\Delta 1$ gene (blue bars) were significantly less susceptible to chlorhexidine than those without carrying qacE $\Delta 1$ gene (red bars) $[p<0.05]$

Naparstek et al. [16], it was reported that $90 \%$ of ST258 K. pneumoniae isolates had an MIC of chlorhexidine of $>128$ $\mathrm{mg} / \mathrm{L}$. Against Escherichia coli, we found that the susceptibility of chlorhexidine has decreased compared with previous studies $[17,18]$, since the MIC distribution observed in this study was 4 to $128 \mathrm{mg} / \mathrm{L}$ (CREC), and 2 to $128 \mathrm{mg} / \mathrm{L}$ (CSEC). Most notably, the CRKP strains carrying qac$E \Delta$ lgene showed less susceptible against chlorhexidine, suggesting there was a linkage between qacE 1 gene and antibiotic resistance genes. It is believed that widespread use of biocides, particularly as antiseptics, could select antibiotic-resistant strains $[8,19]$. However, the role of cepA gene on chlorhexidine resistance is ambiguous. Fang et al. [7] found that the cepA efflux pump is associated with reduced susceptibility to chlorhexidine. Abdulmonem \& Sebastian revealed that as the MIC of chlorhexidine increased, so did the expression of cepA [12]. Yet, Naparstek et al. [16] did not find a correlation between chlorhexidine susceptibility and cepA gene expression.

TCCA is a chlorinated derivative of isocyanurate, with high content of chlorine. It has a strong and long-lasting sterilization effect. In China, it is widely used in medical

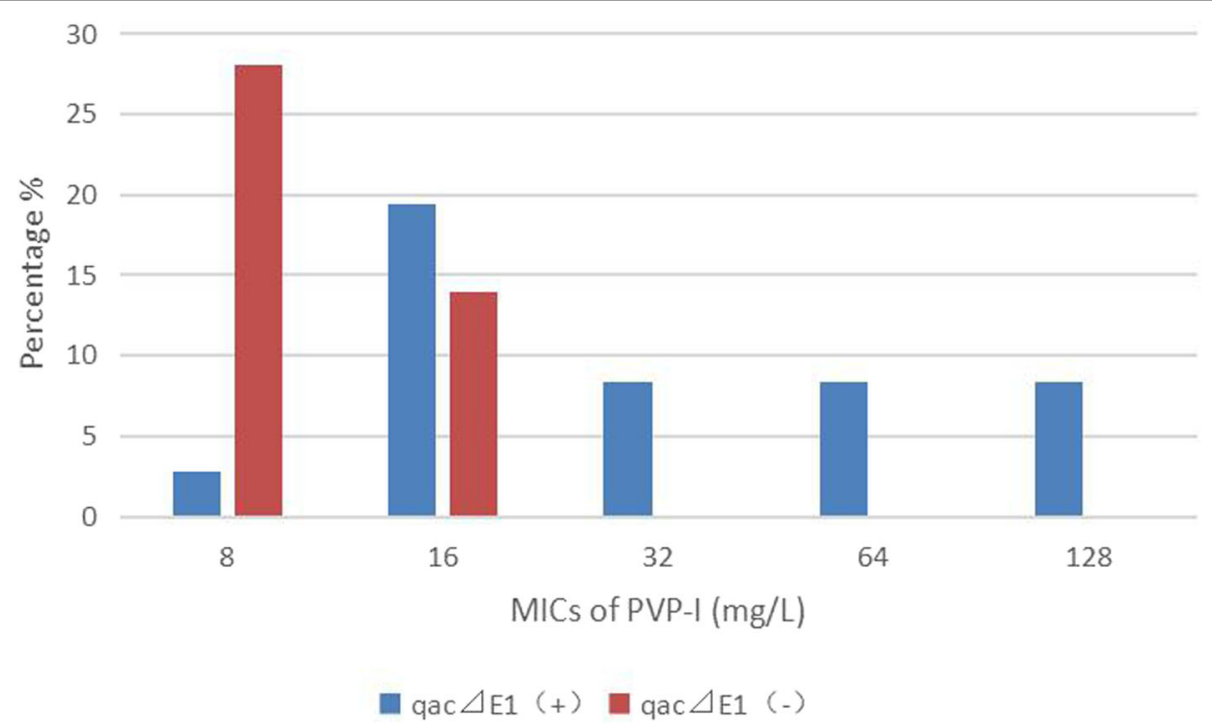

Fig. 3 Distribution of the minimum inhibitory concentrations of PVP-I among 36 CRKP strains. Isolates carrying the gacE $\Delta 1$ gene (blue bars) were significantly less susceptible to PVP-I than those without carrying qacE $\Delta 1$ gene (red bars) $[p<0.05]$ 
health care systems, especially for disinfection of medical devices, equipment, and environment. To our knowledge, this present study is the first study reported the susceptibility of CRE against TCCA in China. We determined that the MIC values of $50 \mathrm{CRE}$ strains against TCCA was 64 to $128 \mathrm{mg} / \mathrm{L}$. In this study, there was no close relationship reported between the resistance genes (qacE $\Delta 1, q a c A / B$ and $c e p A)$ and the TCCA susceptibility. Certainly, there is no doubt that it is of significance to keep monitoring the tendency of the reduced susceptibility against disinfectants.

Povidone-iodine (PVP-I), also known as iodopovidone, is an antiseptic used for skin disinfection before and after surgery. At present, there are few studies on the disinfection effect of iodine on drug-resistant bacteria, especially on CRE $[20,21]$. Our study will help fill this gap. This study showed the $\mathrm{MIC}_{90}$ of $0.1 \%$ PVP-I against the 36 strains of CRKP and 14 strains of CREC was 32 $\mathrm{mg} / \mathrm{L}$, which was consistent with the result of Guo et al. [3] Moreover, among the 36 CRKP isolates, those carrying qacE $\Delta 1$ gene were significantly less susceptible to $0.1 \%$ PVP-I than those without qacE 1 gene, showing that the qacE $\Delta 1$ gene might play a certian role on the mechanism of resistance to iodophor, which needs further investigation.

However, there are certain limitations in the present study. First of all, the sample size was small. More CRE strains are needed for further solid statistical analysis. Second, we provided the necessity for determining the susceptibility of CRE strains against common disinfectants, but the efficacy of the tested disinfectants in eliminating each of these clinically isolated CRE strains from the real-world hospital settings was not evaluated (i.e. on surfaces or medical equipment), which would be further investigated.

\section{Conclusion}

CRE strains collected from patients in our hospital exhibit various degree of resistance to the commonly used disinfectants. CRE strains were highly tolerant to disinfectants, with a higher distribution of disinfectantresistance genes. Incorrect and excessive use of disinfectants has imposed selective pressure on strains, resulting in the high level of resistance to disinfectants and the wide distribution of resistant genes [22]. This study suggested that, priority should be given to monitoring the disinfectants resistance rate of CRE strains in the hospital environment, to ensure that appropriate and effective disinfection measures are taken in the hospital environment to prevent the spread of these lifethreatening resistant strains.

\section{Abbreviations}

CRE: Carbapenem-resistant Enterobacteriaceae; CREC: Carbapenem resistant Escherichia coli; CRKP: Carbapenem resistant Klebsiella pneumoniae;
MBC: Minimum bactericidal concentration; MIC: Minimum inhibitory concentration; PCR: Polymerase chain reaction

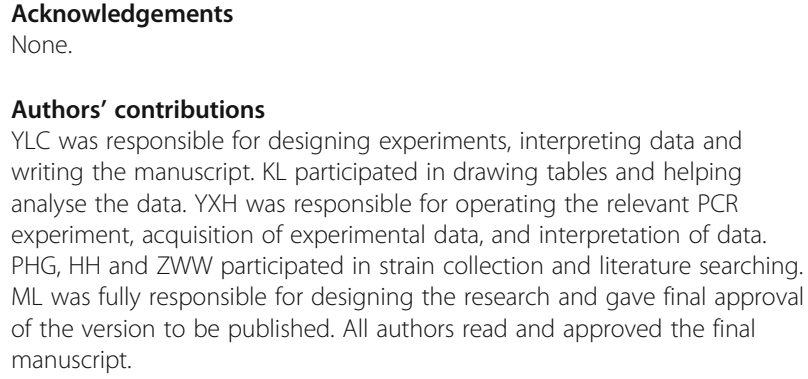
writing the manuscript. KL participated in drawing tables and helping analyse the data. YXH was responsible for operating the relevant PCR experiment, acquisition of experimental data, and interpretation of data. $\mathrm{PHG}, \mathrm{HH}$ and $\mathrm{ZWW}$ participated in strain collection and literature searching. $\mathrm{ML}$ was fully responsible for designing the research and gave final approval of the version to be published. All authors read and approved the final manuscript.

\section{Funding}

This study was not funded by any sponsor or financial institution.

\section{Availability of data and materials}

All data generated or analyzed during this study are included in this published article. The datasets used and/or analysed during the current study are available from the corresponding author on reasonable request.

Ethics approval and consent to participate

This report was approved by the Clinical Research and Ethics Committee of the First Affiliated Hospital of Sun Yat-sen University. Written informed consent was obtained from each participant. All the bacterial isolates in this study were isolated prior to this study.

\section{Consent for publication}

Not applicable since there are no details on individuals reported within the manuscript.

\section{Competing interests}

The authors declare that they have no competing interests.

\section{Author details}

${ }^{1}$ Department of Laboratory Medicine, The First Affiliated Hospital of Sun Yat-sen University, Guangzhou 510080, Guangdong, China. ${ }^{2}$ Guangdong Province Key Laboratory of Malignant Tumor Epigenetics and Gene Regulation, Research Center of Medicine, Sun Yat-Sen Memorial Hospital, Sun Yat-Sen University, Guangzhou 510080, Guangdong, China.

Received: 9 May 2019 Accepted: 21 January 2020

Published online: 30 January 2020

\section{References}

1. Gupta N, et al. Carbapenem-resistant Enterobacteriaceae: epidemiology and prevention. Clin Infect Dis. 2011;53(1):60-7.

2. Ranjan A, et al. Molecular epidemiology and genome dynamics of New Delhi Metallo-beta-lactamase-producing extraintestinal pathogenic Escherichia coli strains from India. Antimicrob Agents Chemother. 2016; 60(11):6795-805

3. Guo W, et al. Determining the resistance of carbapenem-resistant Klebsiella pneumoniae to common disinfectants and elucidating the underlying resistance mechanisms. Pathog Glob Health. 2015;109(4):184-92.

4. Harbarth $\mathrm{S}$, et al. Is reduced susceptibility to disinfectants and antiseptics a risk in healthcare settings? A point/counterpoint review. J Hosp Infect. 2014; 87(4):194-202.

5. Kucken D, Feucht $H$, Kaulfers P. Association of qacE and qacEDelta1 with multiple resistance to antibiotics and antiseptics in clinical isolates of gramnegative bacteria. FEMS Microbiol Lett. 2000;183(1):95-8.

6. Abuzaid A, Hamouda A, Amyes SG. Klebsiella pneumoniae susceptibility to biocides and its association with cepA, qacDeltaE and qacE efflux pump genes and antibiotic resistance. J Hosp Infect. 2012;81(2):87-91.

7. Fang $C T$, et al. Cloning of a cation efflux pump gene associated with chlorhexidine resistance in Klebsiella pneumoniae. Antimicrob Agents Chemother. 2002;46(6):2024-8.

8. Fraise AP. Biocide abuse and antimicrobial resistance--a cause for concern? J Antimicrob Chemother. 2002;49(1):11-2. 
9. Fraud $\mathrm{S}$, et al. Aromatic alcohols and their effect on gram-negative bacteria, cocci and mycobacteria. J Antimicrob Chemother. 2003;51(6):1435-6.

10. Russell AD. Biocide use and antibiotic resistance: the relevance of laboratory findings to clinical and environmental situations. Lancet Infect Dis. 2003; 3(12):794-803.

11. Dai W, et al. Characterization of carbapenemases, extended spectrum betalactamases and molecular epidemiology of carbapenem-non-susceptible Enterobacter cloacae in a Chinese hospital in Chongqing. Infect Genet Evol. 2013;14:1-7.

12. Abuzaid AA, Amyes SG. The genetic environment of the antiseptic resistance genes qacEDelta1 and cepA in Klebsiella pneumoniae. J Chemother. 2015;27(3):139-44.

13. Milstone AM, Passaretti CL, Perl TM. Chlorhexidine: expanding the armamentarium for infection control and prevention. Clin Infect Dis. 2008; 46(2):274-81.

14. Nie $X$, et al. Response of the freshwater alga chlorella vulgaris to trichloroisocyanuric acid and ciprofloxacin. Environ Toxicol Chem. 2008; 27(1):168-73.

15. Steen M. Review of the use of povidone-iodine (PVP-I) in the treatment of burns. Postgrad Med J. 1993;69(Suppl 3):S84-92.

16. Naparstek $L$, et al. Reduced susceptibility to chlorhexidine among extremely-drug-resistant strains of Klebsiella pneumoniae. J Hosp Infect. 2012;81(1):15-9.

17. Beier RC, et al. Chlorhexidine susceptibility, virulence factors, and antibiotic resistance of beta-hemolytic Escherichia coli isolated from neonatal swine with diarrhea. Bull Environ Contam Toxicol. 2005;75(5):835-44

18. Hammond SA, Morgan JR, Russell AD. Comparative susceptibility of hospital isolates of gram-negative bacteria to antiseptics and disinfectants. J Hosp Infect. 1987;9(3):255-64.

19. Prag G, et al. Decreased susceptibility to chlorhexidine and prevalence of disinfectant resistance genes among clinical isolates of Staphylococcus epidermidis. APMIS. 2014;122(10):961-7.

20. Tolcher MC, et al. Chlorhexidine-alcohol compared with povidone-iodine preoperative skin antisepsis for cesarean delivery: a systematic review and meta-analysis. Am J Perinatol. 2019:36(2):118-23.

21. Girardo $P$, et al. Determination of bactericidal minimum concentrations of 3 antiseptics and 1 disinfectant on 580 hospital gram-negative bacilli. Pathol Biol (Paris). 1989;37(5 Pt 2):605-11.

22. Liu WJ, et al. Frequency of antiseptic resistance genes and reduced susceptibility to biocides in carbapenem-resistant Acinetobacter baumannii. J Med Microbiol. 2017;66(1):13-17.

\section{Publisher's Note}

Springer Nature remains neutral with regard to jurisdictional claims in published maps and institutional affiliations.

Ready to submit your research? Choose BMC and benefit from:

- fast, convenient online submission

- thorough peer review by experienced researchers in your field

- rapid publication on acceptance

- support for research data, including large and complex data types

- gold Open Access which fosters wider collaboration and increased citations

- maximum visibility for your research: over $100 \mathrm{M}$ website views per year

At $\mathrm{BMC}$, research is always in progress.

Learn more biomedcentral.com/submissions 